\title{
INEQUALITIES WITH APPLICATIONS INVOLVING $k$-BETA RANDOM VARIABLE
}

\author{
Shahid Mubeen, SAna IQbal And Abdur ReHMan
}

\begin{abstract}
In this paper, we introduce some properties of beta $k$-distribution defined in [1]. We present some inequalities involving beta $k$-distribution via some classical inequalities, like Chebyshev's inequality for synchronous (asynchronous) mappings and Holder's inequality. Also, we discuss the inequalities for harmonic mean, variance and coefficient of variation of $\beta_{k}$ random variable involving the parameter $k>0$. If $k=1$, we get the classical results.
\end{abstract}

Mathematics subject classification (2010): 33B15, 33B20.

Keywords and phrases: $k$-beta distribution, random variable, inequalities.

\section{REFERENCES}

[1] G. Rehman, S. Mubeen, A. Rehman, M. NaZ, On k-Gamma, k-beta distributions and Moment generating Functions, J. Prob. Stat., 2014, Article ID 982013, 6 pages (2014).

[2] R. J. Larsen, M. L. MarX, An Introduction to Mathematical Statistics and Its Applications 5th edition, Prentice-Hall International.

[3] C. Walac, A Hand Book on Statictical Distributations for Experimentalists, last modification 10 september (2007).

[4] N. A. J. Hasting, J. B. Peacock, Statistical Distributions, Butterworth and Company Ltd, (1975).

[5] R. Diaz, E. PARiguan, q, k-Generalized Gamma and Beta Functions, Journal of Nonlinear Mathematical Physics. 12 1, 118-134 (2005).

[6] R. Diaz, E. Pariguan, On hypergeometric functions and k-Pochhammer symbol, Divulg. Mat. 15 2, 179-192 (2007).

[7] C. G. Kokologiannaki, Properties and inequalities of generalized k-gamma, beta and zeta functions, Int. J. Contemp. Math. Sci. 5 14, 653-660 (2010).

[8] C. G. Kokologiannaki, V. Krasnigi, Some properties of k-gamma function, LE Matematiche LXVIII, 13-22 (2013).

[9] V. KrasniQI, A limit for the k-gamma and k-beta function, Int. Math. Forum 5 (33), 1613-1617 (2010).

[10] M. MANSOOR, Determining the k-generalized gamma function $\Gamma_{k}(x)$ by functional equations, Int. J. Contemp. Math. Sci. 4 (21), 1037-1042 (2009).

[11] S. Mubeen, G. M. Habibullah, An integral representation of some k-hypergeometric functions, Int. Math. Forum, 7 (4), 203-207 (2012).

[12] J. ZhANG, H. N. SHI, Two double inequalities for k-gamma and k-Riemann zeta functions, J. Inequal. Appl., 2014: 191 (2014).

[13] S. Mubeen, M. NAZ, G. Rahman, A note on k-hypergeometric diffrential equations, J. Inequal. Spec. Func. 4 (3), 38-43 (2013).

[14] S. Mubeen, G. Rahman, A. Rehman, M. Naz, Contiguous function relations for $k$ hypergeometric functions, ISRN Math. Anal. 2014, Article ID 410801, 6 pages (2014).

[15] S. Mubeen, M. Naz, A. Rehman, G. Rahman, Solutions of k-hypergeometric differential equations, J. Appl. Math. 2014, Article ID 128787, 13 pages, (2014).

[16] S. Mubeen, A. Rehman, F. Shaheen, Properties of k-gamma, k-beta and k-psi functions, Bothalia Journal, 44, 371-379 (2014). 
[17] V. KRASNIQI, Inequalities and monotonicity for the Ration of $k$-gamma function, Scientia Magna, 6 (1), 40-45 (2010).

[18] A. Rehman, S. Mubeen, Some inequalities involving $k$-gamma and $k$-beta functions with applications II, J. Inequal. Appl. 2014, 445 (2014).

[19] K. Pearson, Tables of Incomplete Beta Function, Cambridge University Press 1934 and 2nd Edit. (Editor) (1968).

[20] D. S. Mitrinovic, J. E. PeCARIC, A. M. Fink, Classical and New Inequalities in Analysis, Kluwer Academic Publishers (1993).

[21] P. Kumar, S. P. Singh, S. S. Dragomir, Some inequalities involving beta and gamma functions, Nonlinear Analysis Forum 6 (1), 143-150 (2001).

[22] S. S. DRAGOMiR, R. P. Agrawal, N. S. BARNetT, Inequalities for beta and gamma functions via some classical and new integral inequalities, J. Inequal. Appl. 5, 103-165 (2000).

[23] S. S. DRAGOMIR, S. WANG, Applications of Ostrowski's inequality for the estimation of error bounds for some special means and for some numerical quadrature rules, Applied Mathematics Letters 11 (1), 105-109 (1998).

[24] A. Rehman, S. Mubeen, N. SadiQ, F. Shaheen, Some inequalities involving k-gamma and $k$ beta functions with applications, J. Inequal. Appl. 2014, 224 (2014). 